Check for updates

Cite this: RSC Adv., 2017, 7, 30970

\title{
Fluorinated polyurethane based on liquid fluorine elastomer (LFH) synthesis via two-step method: the critical value of thermal resistance and mechanical properties
}

\author{
Ning Li, (DD ${ }^{a}$ Fanglei Zeng, (D) ${ }^{\mathrm{b}}$ Yu Wang, ${ }^{a}$ Dezhi Qu, ${ }^{a}$ Wenbo Hu, ${ }^{a}$ Yigang Luan, \\ Shuai Dong, ${ }^{\mathrm{C}}$ Jianjun Zhang $^{\mathrm{d}}$ and Yongping Bai ${ }^{* a}$
}

\begin{abstract}
Until now, only few hydroxy-terminated fluorinated monomers were reported as soft segment. In this work, based on a novel hydroxy-terminated liquid fluorine elastomer (LFH), a series of FPUs were synthesized via a two-step method. Flexible soft segment polytetrahydrofuran glycol (PTMG) was applied as the second soft segment. FTIR and GPC results indicated that the fluorinated groups were introduced into the structures of copolymers, and all the monomers were copolymerized successfully. TGA, DMTA and conventional mechanical analysis show that FPU gains optimal thermal stability and mechanical properties when the dosage of LFH is increased to a critical value of $18 \mathrm{wt} \%$, even after the cured films being immersed into hot water and oil. Additionally, the surface properties of FPUs can be highly changed as a small amount of fluoride (6 wt\%) is introduced into the structures of copolymers, due to the effect of fluorine enrichment. Consequently, LFH can effectively improve the thermal stability, mechanical properties, water resistance and organic solvent resistance of polyurethane within limits. Besides, these mentioned controllable properties of FPU can be achieved by changing the dosage of LFH. This work will help to achieve the best balance between performance and cost in industrial production.
\end{abstract}

Received 21st April 2017

Accepted 3rd June 2017

DOI: $10.1039 / c 7 r a 04509 c$

rsc.li/rsc-advances

\section{Introduction}

Fluorinated polyurethanes (FPUs) ${ }^{1,2}$ are a class of polymer materials with outstanding properties. Owing to the high electronegativity and small atomic radius of fluorine atoms, and the short C-F bond length, FPUs not only possess outstanding mechanical properties and two-phase microstructure from polyurethane, ${ }^{3-5}$ but also own the virtues of fluoropolymers, such as low surface energy, hydrophobicity, lipophobicity and high thermal stability. ${ }^{6-12}$ Accordingly, FPUs have aroused wide attention of researchers around the world since Lovelace firstly synthesized fluorinated polyurethane in 1958 via the reaction between isocyanate and fluorinated glycol. ${ }^{13}$ Until now, the fluorinated monomers such as fluorinated diisocyanate, ${ }^{\mathbf{1 4}}$ glycol, ${ }^{15}$ polyether glycol, ${ }^{16-19}$ chain extender, ${ }^{20-24}$ side group ${ }^{25}$ and end-capper ${ }^{26}$ could all be used to synthesize FPUs. Consequently, FPUs have great application prospects in the areas of

${ }^{a}$ School of Chemistry and Chemical Engineering, Harbin Institute of Technology, Harbin 150001, China.E-mail: baifengbai@hit.edu.cn

${ }^{b}$ School of Materials Science \& Engineering, Beijing Institute of Technology, Beijing 100081, China

${ }^{c}$ College of Materials Science and Engineering, Key Laboratory of Carbon Fiber and Functional Polymers of Ministry of Education, Beijing University of Chemical Technology, Beijing 100029, China

${ }^{d}$ FoShan NanHai Gotop Packaging Material Co., Ltd, Foshan 528225, China protective coatings, the paint industry, leather decoration and medicine. $^{27-31}$

However, until now, only a few kinds of hydroxy-terminated fluorinated monomers were reported, and even fewer of them could balance the benefit and performance of FPUs. "HO-VDFco-HFP-OH" (LFH) is a kind of hydroxyl terminated poly (vinylidene fluoride-hexafluoropropylene) (VDF = vinylidene fluoride, HFP = hexafluoropropylene). It is a kind of hydroxyl terminated liquid fluorine elastomer with low molecular weight prepared in our laboratory. As one of reactants, it not only inherits some characteristics of solid-state fluorine rubber, such as low surface energy, high chemical stability and water resistance, ${ }^{32-35}$ but also remedies the defects of the solid-state fluorine rubber in mobility, sampling convenience and processing. LFH with active group-terminated can be introduced to FPU as the second soft segments, which could realize the controllable property of FPUs by adjusting the ratio of two soft segments. This new kind of FPUs and the critical value of the ratio between the soft segments have not been reported, which could be regarded as the "shining point" of this paper.

In this paper, a series of fluorinated polyurethanes (FPUs) were synthesized via a two-step method. 4,4-Diphenylmethane diisocyanate (MDI) and 1,4-butylene glycol (BDO) were applied as hard segments, two polyester polyols (hydroxy-terminated liquid fluorine elastomer (LFH) and polytetrahydrofuran 
glycol (PTMG)) were used as soft segments, dibutyltin dilaurate (DBTEL) was used as catalyst. The obtained FPUs were characterized by GPC, FTIR, NMR. TGA, dynamic mechanical analysis (DMTA) and conventional mechanic analysis showed that FPUs gained optimal thermal stability and mechanical property when the dosage of LFH increased to a critical value (18 wt\%), even after the cured films being immersed into hot water and oil. Besides, the surface property of FPUs can be reduced rapidly once a small amount of fluoride is introduced, due to the effect of fluorine enrichment. Consequently, LFH can effectively improve the thermal stability, mechanical property, water and organic solvent resistance of polyurethane within limits (the dosage of LFH is between 6 and $18 \mathrm{wt} \%$ ) and the controllable properties of FPU can be achieved via changing the dosage of LFH. It is highly beneficial to reduce the cost of the product based on these kind of FPUs.

\section{Experimental section}

\section{Materials}

Carboxyl-terminated liquid fluoropolymer (HOOC-VDF-co-HFP$\mathrm{COOH})$ was prepared as the previous report. ${ }^{36}$ Polytetrahydrofuran glycol (PTMG, $M_{\mathrm{w}}=2050, M_{\mathrm{w}} / M_{\mathrm{n}}=1.21$ ) was obtained from Jining Hua Kai Resin co., Ltd. Sodium borohydride $\left(\mathrm{NaBH}_{4}\right)$ and iodine $\left(\mathrm{I}_{2}\right)$ was obtained from GuoYao Chemical Reagent Co., Ltd. 4,4-Diphenylmethane diisocyanate (MDI) was supplied by Bayer Industrial Corporation. 1,4Butylene glycol (BDO) and ethyl acetate were provided by Beijing Chemical Plant. Dibutyltin dilaurate (DBTDL) was purchased from Tianjin Fu Chen Chemical Co., Ltd. PTMG was dried in a vacuum oven at $50{ }^{\circ} \mathrm{C}$ for $2 \mathrm{~h}$.

\section{Synthesis of LFH}

Hydroxyl-terminated liquid fluorine elastomer "HO-VDF-coHFP-OH" (LFH) was prepared through reduction reaction of carboxyl-terminated liquid fluoropolymers as shown in Scheme 1 . The dry THF $(10 \mathrm{~mL})$ solution with iodine $(5.00$ mmol) was added dropwise to the stirred dry THF $(20 \mathrm{~mL})$ solution with $\mathrm{NaBH}_{4}(10.00 \mathrm{mmol})$ under argon at $0{ }^{\circ} \mathrm{C}$ over $45 \mathrm{~min}$. Then, the dry THF $(100 \mathrm{~mL})$ solution with carboxylterminated liquid fluoropolymers $(10.00 \mathrm{~g}, \quad 3.85 \mathrm{mmol}$ carboxyl group) was added the above solution, and reacted at $70{ }^{\circ} \mathrm{C}$ for $5 \mathrm{~min}$. After that, the mixture solution was cooled to $0^{\circ} \mathrm{C}$, and the excess hydride was carefully destroyed by dropwise addition of $2 \mathrm{~mol} \mathrm{~L}^{-1}$ hydrochloric acid $(10.00 \mathrm{~mL})$. After filtering to separate the complex of residual hydride and then excess deionized water was added into the filtrate. The mixture was extracted with THF for 3 times and the organic layer was

$$
\text { LFH: }
$$

Scheme 1 The synthesis route of hydroxyl terminated liquid fluorine elastomer "HO-VDF-CO-HFP-OH" (LFH). collected. The solution was dried with magnesium sulfate. The resultant product was concentrated by a rotary evaporator. A viscous yellow liquid was obtained in a yield of $93 \% . M_{\mathrm{w}}$ of LFH is 2400 , PDI $=1.56$ (estimated by gel permeation chromatograph (GPC) in THF on the basis of polystyrene calibration).

\section{Synthesis of PreFPU}

FPUs were synthesized via a two-step method. Scheme 2 shows the synthesis route of fluorinated polyurethane prepolymer (PreFPU). In this work, ordinary polyurethane (FPU-1) and four fluorinated polyurethanes (FPU-2, FPU-3, FPU-4, FPU-5) were successfully synthesized, the dosages of LFH in these FPUs are $0 \mathrm{wt} \%, 6 \mathrm{wt} \%, 12 \mathrm{wt} \%, 18 \mathrm{wt} \%$, and $24 \mathrm{wt} \%$, respectively. The process of synthesis of FPU-3 (18 wt\%) was illustrated in detail below as an example. MDI ( $6.08 \mathrm{~g})$ was added into a round bottomed flask equipped with condenser pipe and stirring system under nitrogen atmosphere. The flask was heated to $50{ }^{\circ} \mathrm{C}$ and maintained the temperature for $1 \mathrm{~h}$ to remove the water in MDI. PTMG (10.60 g) and LFH ( $3.70 \mathrm{~g})$ were dried in a vacuum oven at $50{ }^{\circ} \mathrm{C}$ for $2 \mathrm{~h}$ and dissolved into ethyl acetate $(20 \mathrm{~mL})$. Then, DBTDL $(0.15 \mathrm{~g})$ was added into the above the solution. The mixture solution was stirred at the stirring speed of $150 \mathrm{rpm}$. After feeding raw material, the stirring speed was increased to $250 \mathrm{rpm}$. After reacting at $80^{\circ} \mathrm{C}$ for $4 \mathrm{~h}$, the reaction equipment was cool down to room temperature. Finally, the yellow viscous product PreFPU was obtained.

\section{Synthesis of FPU}

The synthesis route of fluorinated polyurethane (FPU) is showed in Scheme 3. BDO (5.00 g) was added to the prepared PreFPU in the round bottomed flask, and stirred at the speed of $250 \mathrm{rpm}$ for about $2 \mathrm{~min}$. Then, the mixture was poured onto the treated mold, and put horizontally in a vacuum oven for $40 \mathrm{~min}$, and dried at $110{ }^{\circ} \mathrm{C}$ in ordinary pressure environment for $10 \mathrm{~h}$. Finally, FPU-3 film was obtained. Elemental analysis calculated (\%) for FPU-3: C, 40.74; H, 5.73. Found (\%): C, 40.11; H, 5.39.

FPU-1 ( $0 \mathrm{wt} \%)$ was prepared via the similar procedure of FPU-3, the difference is that LFH was not be added into the reaction system.

\section{Synthesis of FPU}

The synthesis route of fluorinated polyurethane (FPU) is showed in Scheme 3. BDO $(5.00 \mathrm{~g})$ was added to the prepared PreFPU in

$$
\text { PreFPU: }
$$

Scheme 2 The synthesis route of fluorinated polyurethane prepolymer (PreFPU). 


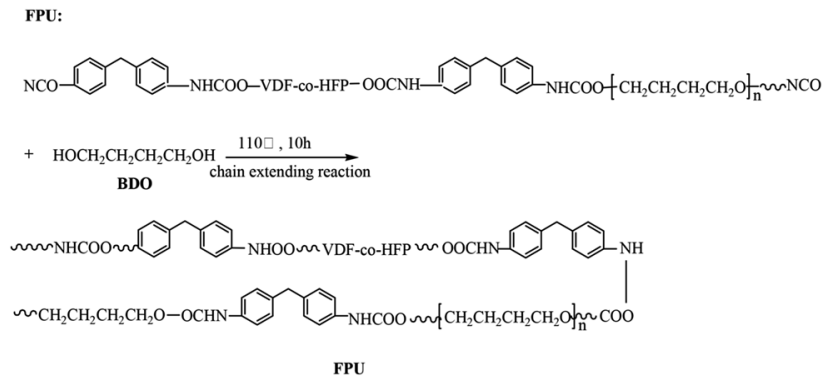

Scheme 3 The synthesis route of fluorinated polyurethane (FPU).

the round bottomed flask, and stirred at the speed of $250 \mathrm{rpm}$ for about $2 \mathrm{~min}$. Then, the mixture was poured onto the treated mold, and put horizontally in a vacuum oven for $40 \mathrm{~min}$, and dried at $110{ }^{\circ} \mathrm{C}$ in ordinary pressure environment for $10 \mathrm{~h}$. Finally, FPU-3 film was obtained. Elemental analysis calculated (\%) for FPU-3: C, 40.74; H, 5.73. Found (\%): C, 40.11; H, 5.39.

FPU-1 (0 wt $\%)$ was prepared via the similar procedure of FPU-3, the difference is that LFH was not be added into the reaction system.

\section{Characterization}

Fourier transform infrared spectroscopy (FTIR) measurements were performed using a Nicolet Nexus 670 instrument, USA. Molecular weights $\left(M_{\mathrm{w}}\right.$ and $\left.M_{\mathrm{n}}\right)$ and polydispersity indexes (PDI) of the polymers were estimated by a Waters gel permeation chromatography (GPC) system (Waters, 515 HPLC Pump) using THF as an eluent on the basis of polystyrene calibration and refractive index (RI) detector. Tensile strength and elongation at break were tested as a Chinese Standard (GBT 528-2009) using an RGT-5 electronic universal testing machine manufactured by Shenzhen Reger Instrument Co., Ltd. Hardness was tested by Shore Hardness tester as a Chinese Standard (GBT 531-1999). Thermal stability of the polymer was verified by a Perkin-Elmer TGS-2 analyzer using $1.5 \mathrm{mg}$ of the sample in $\mathrm{Al}_{2} \mathrm{O}_{3}$ crucible under nitrogen ambience at a heating rate of $20{ }^{\circ} \mathrm{C} \mathrm{min}^{-1}$. Dynamic mechanical thermal analysis (DMTA) was carried out on a dynamic thermal mechanical analyzer manufactured by DMA Q-800 (American Rheometric Scientific Company). Melting point $\left(T_{\mathrm{m}}\right)$ of FPU was investigated via differential scanning calorimetry (DSC) with a heating rate of $10^{\circ} \mathrm{C} \mathrm{min}^{-1}$ and in the temperature range from 50 to $250^{\circ} \mathrm{C}$, using DSC882e (METTLER-TOLEDO Co., Ltd.). Elemental analysis (C, H) was performed with a Perkin-Elemer 2400 II Elemental Analyzer. The viscoelastic behavior of FPU was investigated at a frequency of $1 \mathrm{~Hz}$, strain $0.02 \%$, with a heating rate of $5{ }^{\circ} \mathrm{C} \mathrm{min}^{-1}$ and in the temperature range from -150 to $150^{\circ} \mathrm{C}$. The measurements were performed on rectangular specimens $(15.0 \mathrm{~mm} \times 7.0 \mathrm{~mm}$ $\times 1.0 \mathrm{~mm} \pm 0.2 \mathrm{~mm}$ ), under stretch mode, using stretch fixture (rectangle) geometry. The static contact angle of FPU films were measured by the sessile drop method at $25^{\circ} \mathrm{C}$ using a Cam 200 optical contact angle meter (Dataphysics Instruments Co., Ltd.). Distilled water and ethylene glycol were used in the measurement. Typically, five angle measurements were made and the data were averaged. Chemical resistance of FPU film was characterized according to ASTM D471-02. The FPU films were immersed in the media (cyclohexane, $37 \% \mathrm{HCl}$ and $45 \% \mathrm{NaOH}$, respectively) at a room temperature for $168 \mathrm{~h}$ and water of $90^{\circ} \mathrm{C}$ for 48 hours. The weight change of the films was calculated by using the following equation:

$$
\text { Weight change }(\%)=\left[\left(W_{2}-W_{1}\right) / W_{1}\right] \times 100,
$$

where $W_{1}$ and $W_{2}$ represent the film weights before and after immersed into the media, respectively.

\section{Results and discussion}

\section{${ }^{1} \mathrm{H}$-NMR and ${ }^{19} \mathrm{~F}$-NMR analysis of $\mathrm{LFH}$}

The structures of the hydroxyl terminated liquid fluorine elastomer (LFH) and the precursor-carboxyl terminated liquid fluorine elastomer (LFE) were confirmed by ${ }^{1} \mathrm{H}$ spectroscopy in Fig. 1a. Compared with LFE, LFH exhibits a new peaks at $3.6 \mathrm{ppm}$ ascribed to the connected $-\mathrm{CH}_{2}$ group, which confirms the formation of $\mathrm{LFH}$.
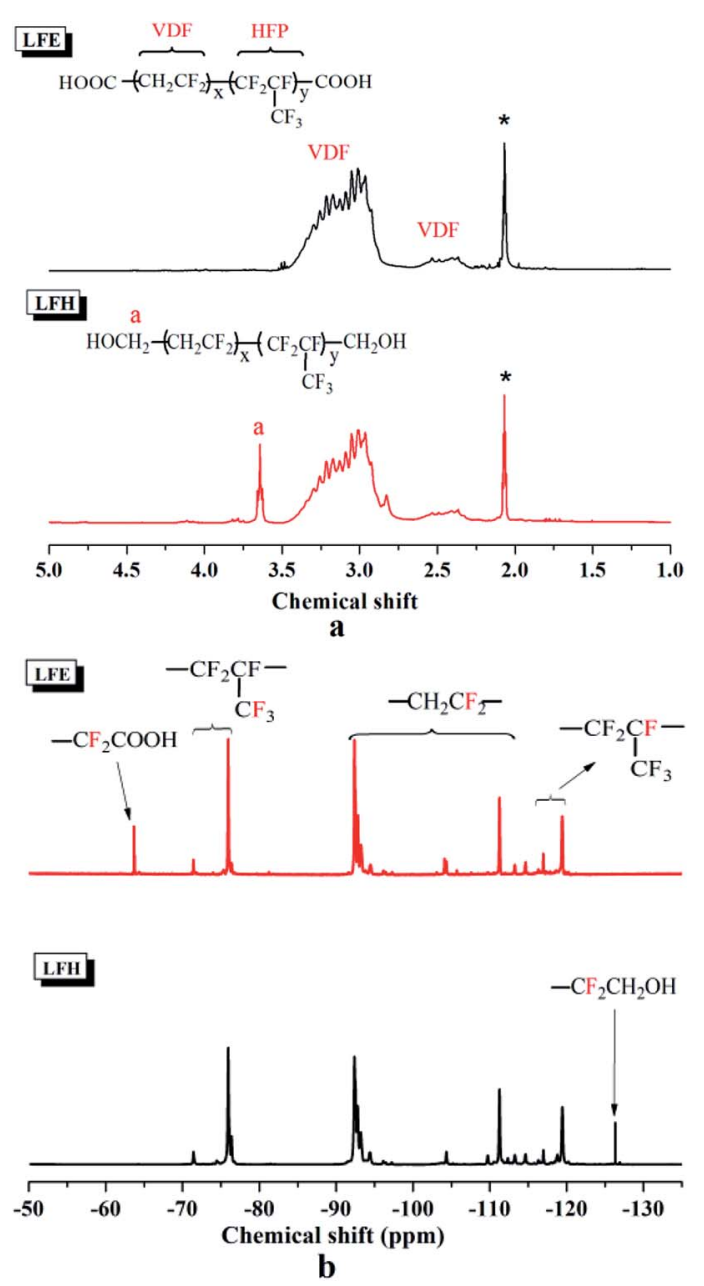

Fig. $1{ }^{1} \mathrm{H}$ NMR (a) and ${ }^{19} \mathrm{~F}$ NMR (b) spectra of hydroxyl terminated liquid fluorine elastomer (LFH) and its precursor LFE in acetone- $d_{6}$. The solvent peaks are marked with asterisks. 
To further characterize LFH, ${ }^{19} \mathrm{~F}$ NMR spectroscopy also is an effective method. The ${ }^{19} \mathrm{~F}$ NMR spectra of LFH and LFE can be found in Fig. 1b. For LFE, multiple broad peak at $\delta=-63$ to $-64 \mathrm{ppm},-71$ to $-77 \mathrm{ppm},-94$ to $-116 \mathrm{ppm},-116$ to $120 \mathrm{ppm}$ ascribes to the groups of $-\mathrm{CF}_{2} \mathrm{COOH}-\mathrm{CF}_{2} \mathrm{CF}\left(\mathrm{CF}_{3}\right)^{-},-\mathrm{CH}_{2} \mathrm{CF}_{2}-$ and $-\mathrm{CF}_{2} \mathrm{CF}\left(\mathrm{CF}_{3}\right)-,^{36,40,41}$ respectively. And the curve of $\mathrm{LFH}$ exhibits a new peak at -125 to $-127 \mathrm{ppm}$, it ascribes to chemical shift of $\mathrm{F}$ atom of $-\mathrm{CF}_{2} \mathrm{CH}_{2} \mathrm{OH}$. All above confirm the successful formation of hydroxyl-terminated liquid fluoropolymer (LFH).

\section{Analysis of FPU}

The FTIR spectrum of fluorinated polyurethane (FPU) was showed in Fig. 2. Meanwhile, the spectra of polytetrahydrofuran glycol (PTMG), hydroxy-terminated liquid fluorine elastomer (LFH), 1,4-butylene glycol (BDO) and 4,4-diphenylmethane diisocyanate (MDI) were also given in the same figure for comparison. For FPU, the urethane $\mathrm{N}-\mathrm{H}$ stretch absorption peak around $3340 \mathrm{~cm}^{-1}$, the $-\mathrm{C}-\mathrm{O}-\mathrm{C}$ peak at $1261 \mathrm{~cm}^{-1}$ and the strong urethane $\mathrm{C}=\mathrm{O}$ peak around $1735 \mathrm{~cm}^{-1}$ prove the existence of -NHCOO-. Moreover, the strong absorption peaks at 884,1210 , and $1400 \mathrm{~cm}^{-1}$ are ascribed to the stretching vibration of $-\mathrm{CF}_{3}, \mathrm{CF}_{2}-$ and $-\mathrm{FCH}_{2}$, respectively. And the same peaks also exist both in the FTIR spectra of the precursor LFH and PreFPU, which clearly demonstrate that fluorinated

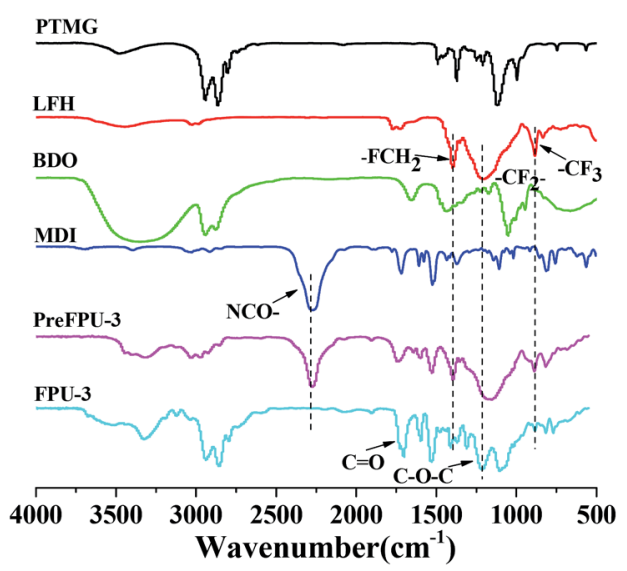

Fig. 2 The FTIR spectra of polytetrahydrofuran glycol (PTMG), hydroxy-terminated liquid fluorine elastomer (LFH), 1,4-butylene glycol (BDO), 4,4-diphenylmethane diisocyanate (MDI), fluorinated polyurethane prepolymer (PreFPU-3) and fluorinated polyurethane (FPU-3).

Table $1 M_{\mathrm{w}}$ of PreFPU and FPU synthesised by PTMG and LFH ${ }^{a}$

\begin{tabular}{llllll}
\hline Dosage of LFH & $0 \mathrm{wt} \%$ & $6 \mathrm{wt} \%$ & $12 \mathrm{wt} \%$ & $18 \mathrm{wt} \%$ & $24 \mathrm{wt} \%$ \\
\hline$M_{\mathrm{w}}$ (PreFPU) & 4573 & 5650 & 6320 & 6164 & 6211 \\
PDI (PreFPU) & 1.25 & 1.33 & 1.31 & 1.29 & 1.37 \\
$M_{\mathrm{w}}$ (FPU) & 19932 & 43176 & 399087 & 41121 & 42348 \\
PDI (FPU) & 1.76 & 1.79 & 1.81 & 1.76 & 1.91
\end{tabular}

${ }^{a} M_{\mathrm{w}}$ of LFH is 2400 . Estimated by gel permeation chromatograph (GPC) in THF on the basis of polystyrene calibration. polyurethane have the same backbone structure as its precursor LFH. These new peaks indicate that the expected fluorinated polyurethane (FPU) has been successfully prepared. Additionally, the absorption peak at $2275 \mathrm{~cm}^{-1}$ (-NCO) disappear, indicating that the polyreaction has been consumed completely. And there was not unreacted prepolymer residue which could be confirmed by utilizing the "Chemical titration" method. ${ }^{42-45}$ Elemental analysis calculated (\%) for FPU-3: C, 31.29; H, 7.05. Found (\%): C, 31.26; H, 7.02.

The comparisons of molecular weight $\left(M_{\mathrm{w}}\right)$ and PDI $\left(M_{\mathrm{w}} / M_{\mathrm{n}}\right)$ of fluorinated polyurethane prepolymer (PreFPU) and fluorinated polyurethane (FPU) were presented in Table 1. Compared with PreFPUs, the molecular weight of FPUs increased hugely, which indicated that polyreaction of FPUs were processed successfully.

\section{Thermal resistance property}

Thermal gravimetric analysis (TGA) technique was utilized to study the thermal resistance of the FPUs. The TGA curves of the polyurethanes (FPU-1, FPU-2, FPU-3, FPU-4 and FPU-5) are showed in Fig. 3. In order to evaluate the initial decomposition behavior of the polymers, $T_{5}$ is defined as the temperature at which the resin loses $5 \%$ of its original weight, $T_{10}$ is defined as the temperature at which the resin loses $10 \%$ of its original weight. The $T_{5}$ and $T_{10}$ values and the char yields $\left(Y_{\mathrm{c}}\right)$ at $800{ }^{\circ} \mathrm{C}$ of the five polyurethanes (FPU-1, FPU-2, FPU-3, FPU-4 and FPU-5) have been concluded in the Table 2. Obviously, the $T_{5}$ values for FPU-1, FPU-2, FPU-3, FPU4 and FPU-5 are 267, 284, 295, 304 and $305{ }^{\circ} \mathrm{C}$, respectively. And the $T_{10}$ values of them are $285,303,315,325$ and $325{ }^{\circ} \mathrm{C}$, respectively. These data indicate that these fluorinated polyurethanes (FPU-2, FPU-3, FPU-4 and FPU-5) have higher thermal stability than the fluorine-free polyurethane (FPU-1). On one hand, the ultimate char yield of these five polyurethanes at $800{ }^{\circ} \mathrm{C}$ are $4.0 \%$, $10.1 \%, 14.2 \%, 19.1 \%$ and $17.3 \%$, respectively. Obviously, with the increase of the fluorine content, the decomposition temperature and the ultimate char yield all increased. This result indicated that the fluoric group could effectively reduce the degradation rate of fluorinated polyurethanes. That is because that fluorine atoms possess stronger electronegativity and bond energy, shorter atomic radius than carbon atom. The fluorine atoms would protect the

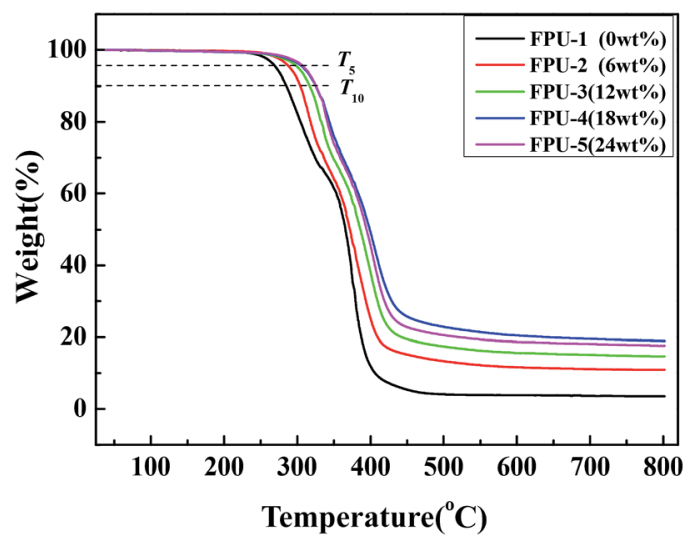

Fig. 3 TGA curves of polyurethane with different dosage of LFH at a heating rate of $10^{\circ} \mathrm{C} \mathrm{min}^{-1}$ in $\mathrm{N}_{2}$. 
Table 2 Thermal properties of FPU-1, FPU-2, FPU-3, FPU-4 and FPU5 in $\mathrm{N}_{2}$

\begin{tabular}{lllll}
\hline No. & Polyurethane & $T_{5} /{ }^{\circ} \mathrm{C}$ & $T_{10} /{ }^{\circ} \mathrm{C}$ & $Y_{\mathrm{c}}$ at $800{ }^{\circ} \mathrm{C}, \%$ \\
\hline 1 & FPU-1 & 267 & 285 & 4.0 \\
2 & FPU-2 & 284 & 303 & 10.1 \\
3 & FPU-3 & 295 & 315 & 14.2 \\
4 & FPU-4 & 304 & 325 & 19.1 \\
5 & FPU-5 & 305 & 325 & 17.3 \\
\hline
\end{tabular}

carbon framework of the polymer. On the other hand, with the increase of the ratio of soft segment contained fluorine, the MDI hard segment ratio decreased, which would decrease the thermal resistance of the FPU. ${ }^{37,38}$ this could explain why the $Y_{\mathrm{c}}$ of FPU-5 $(17.3 \%)$ at $800{ }^{\circ} \mathrm{C}$ less than FPU-4 (19.1\%). Hence, in order to obtain the FPU with best thermal stability, we could control the dosage of LFH and make it not more than $24 \%$, and $18 \%$ is the best choice.

\section{Dynamic mechanical analysis}

Thermo-mechanical properties of the obtained FPUs were studies by means of dynamic mechanical thermal analysis
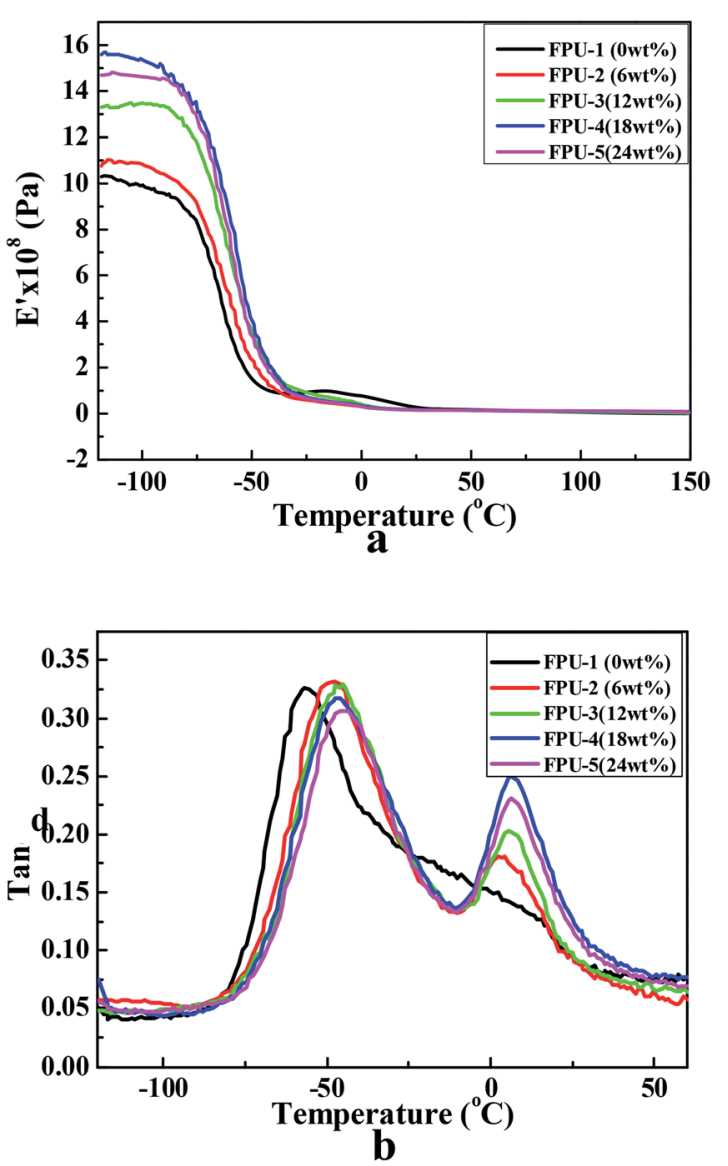

Fig. 4 Storage modulus (a) and the dissipation factor ( $\tan \delta$ ) (b) of fluorinated polyurethane with different dosage of LFH between -125 and $150^{\circ} \mathrm{C}$.
(DMTA) which allows different types of transitions and relaxations to be detected and related to the structure and morphology of the samples. Fig. 4(a) and (b) shows the storage modulus and the dissipation factor $(\tan \delta)$ of polyurethanes with different dosages of LFH. As shown in Fig. 3a, the storage modulus of all polyurethanes stay above $10^{9} \mathrm{~Pa}$ between -125 and $-80{ }^{\circ} \mathrm{C}$, attributing to the lower temperature than the glass transition temperature $\left(T_{\mathrm{g}}\right)$ of flexible chain. So the chain could not freely move and the stress relaxation could not appear. Besides, the addition of soft segment containing fluorine (LFH) leads to an obvious increase in the storage modulus value between -125 and $-25{ }^{\circ} \mathrm{C}$, because the presence of fluorine atoms increased the number of hydrogen bonds and strengthened intermolecular interaction force in polyurethane. When the dosage of $\mathrm{LFH}$ is $18 \mathrm{wt} \%$, the ratio of the hard segment related to the rigid of FPU did not decrease too much, the interaction between soft and hard segments reached the best points (status), which could explain why the storage modulus of FPU is highest.

As shown in Fig. 4b, the curves of dissipation factor $(\tan \delta)$ apparently exhibited two peaks at low temperature $\left(-80\right.$ to $\left.0{ }^{\circ} \mathrm{C}\right)$ and at high temperature $\left(0-50{ }^{\circ} \mathrm{C}\right)$, indicating that these five polyurethanes have two glass transition temperature $\left(T_{\mathrm{g}}\right)$. It may be caused by the microphase separation between the flexible soft segment and the rigid hard segment. With the increase of the ratio of the soft segment containing fluorine, the peak intensity at the high temperature also increased gradually, because $T_{\mathrm{g}}$ is susceptible to the introduction of soft segment containing fluorine with high molecular weight. The $T_{\mathrm{g}}$ of fluorine-free polyurethane in low temperature area is $-56{ }^{\circ} \mathrm{C}$, obviously, which is lower than fluorinated polyurethanes, indicating that the introduction of pendant group $\left(-\mathrm{CF}_{3}\right)$ reduced the flexibility of the soft segment, the high electronegativity promoted the interaction between soft and hard segments. As a result, these fluorine-contained polyurethanes (FPU-2, FPU-3, FPU-4 and FPU-5) have higher thermal stability than the fluorine-free polyurethane (FPU-1). Furthermore, with the increase of fluorine content, the difference value between the $T_{\mathrm{g}}$ of hard and soft segments became smaller. At the same

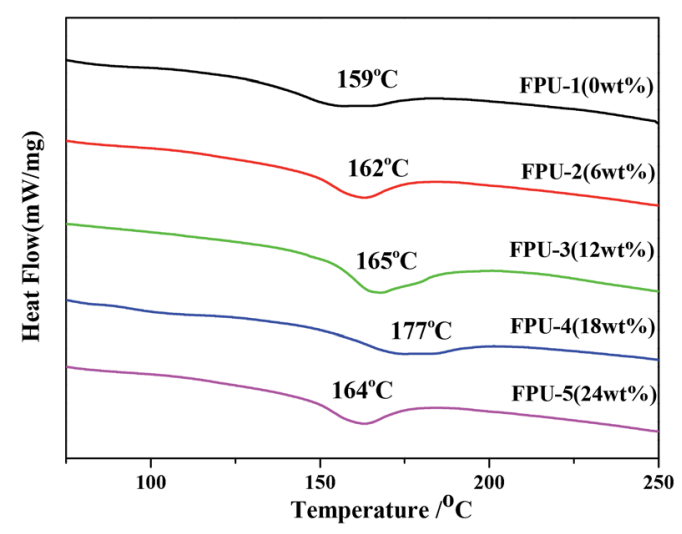

Fig. 5 DSC curves of polyurethane with different dosage of LFH at a heating rate of $10^{\circ} \mathrm{C} \mathrm{min}^{-1}$ in $\mathrm{N}_{2}$. 
time, the microphase separation degree decreased, and the compatibility became better.

\section{DSC analysis}

Differential scanning calorimetry (DSC) technique is an important method to study the aggregative states and thermal transformation of polymer materials, it is necessary to study melting point $\left(T_{\mathrm{m}}\right)$ of FPUs. As shown in Fig. 5, with the temperature increasing, these FPUs show endothermic peaks at the rang of $150{ }^{\circ} \mathrm{C}$ to $200^{\circ} \mathrm{C}$. Melting range of each curve is long and the shape of each peak is not sharp, it attribute to the microphase separation structures of FPUs which are consistent with the DMTA findings (Fig. 4). Besides, with the dosage of LFH increase, $T_{\mathrm{m}}$ rise at the beginning and then decrease, and FPU-4 (18 wt\%) have the highest $T_{\mathrm{m}}\left(177^{\circ} \mathrm{C}\right)$. The main reason may be that the introduction of fluorine containing side groups would increase the number of the $\mathrm{H} \cdots \mathrm{F}$ hydrogen bonds, which would make $\Delta H$ larger. According to the formula: $T_{\mathrm{m}}=\Delta H / \Delta S$, $T_{\mathrm{m}}$ grows. ${ }^{46}$ what is more, random copolymerization is another factor that make $T_{\mathrm{m}}$ larger. However, with the dosage of LFH increase, the reduction of hard segment ratio would make $T_{\mathrm{m}}$ reduce.

\section{Conventional mechanic analysis at different temperature}

Fig. 6 shows the tensile strength and elongation at break curves of fluorinated polyurethanes (FPUs) with different dosages of LFH (0 wt $\%, 6 \mathrm{wt} \%, 12 \mathrm{wt} \%, 18 \mathrm{wt} \%$, and $24 \mathrm{wt} \%$ ) at $25{ }^{\circ} \mathrm{C}$, $100{ }^{\circ} \mathrm{C}, 200{ }^{\circ} \mathrm{C}$ and $300{ }^{\circ} \mathrm{C}$, respectively. All the data are measured after FPUs being heated at each temperature for $40 \mathrm{~min}$. Five measurements were made and the data were averaged. As shown in Fig. 6, at each temperature, both of tensile strength and elongation at break of FPUs increase as the dosage of soft segment containing fluorine increase at the beginning and then begin to decrease when the dosage of LFH increase to $18 \mathrm{wt} \%$. At $25^{\circ} \mathrm{C}$, as the dosage of LFH increase to 18 wt $\%$, polyurethane gains the best mechanical properties. The tensile strength is as high as $24.3 \mathrm{MPa}$, and the elongation at break is as high as $558.6 \%$. Even in $300{ }^{\circ} \mathrm{C}$, these two parameters still reached $17.8 \mathrm{MPa}$ and $450.0 \%$, respectively. At the same time, to evaluate the effect of dosage of LFH on the mechanical properties of FPU at different temperatures, $\Delta_{\mathrm{Rm}}$ is defined as the value of decline of tensile strength from $25^{\circ} \mathrm{C}$ to $300{ }^{\circ} \mathrm{C}$. Obviously, $\Delta_{\mathrm{Rm} 0}>\Delta_{\mathrm{Rm} 6}>\Delta_{\mathrm{Rm} 12}>\Delta_{\mathrm{Rm} 18}>\Delta_{\mathrm{Rm} 24}$, it shows a tendency of decrease with the increase of LFH dosage. The more of the fluoride soft segment content, the less decline of mechanical property. It is attributed to the great rigidity of the main chain of fluoro-carbon PTMG and the high polarity of fluoride groups. With the increase of the ratio of the fluoride group, the ratio of soft segment containing fluorine increased, meanwhile, cohesive energy of the F-MDI molecule in the micro area of hard segment increased, so the mechanical properties of FPU increased. However, with the increase of fluoro-containing soft segment, the ratio of hard segments which played the most important role in mechanical strength decrease. Therefore, when the ratio of the soft segment of fluoride increases to a critical value, the hard segment (BDO and MDI) plays the main
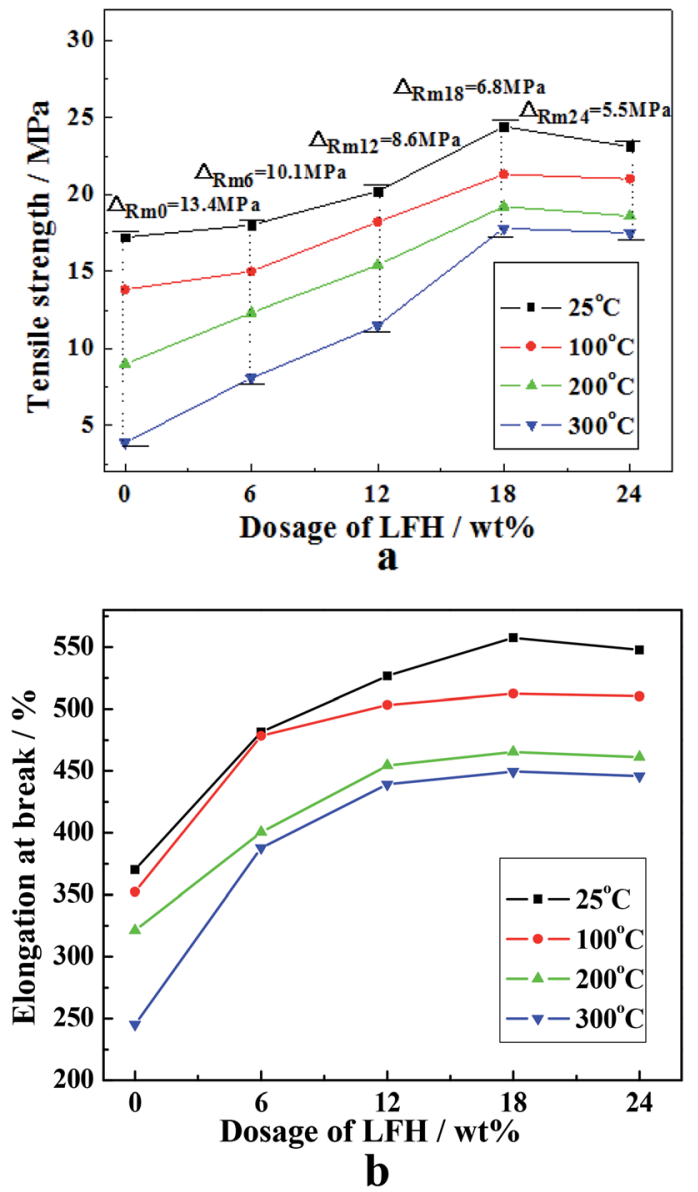

Fig. 6 Tensile strength (a) and elongation at break (b) curves of fluorinated polyurethane with different dosage of LFH (0 wt\%, $6 \mathrm{wt} \%$, $12 \mathrm{wt} \%, 18 \mathrm{wt} \%$, and $24 \mathrm{wt} \%)$ at different temperature.

role. As a result, there was a slight decline of tensile strength when the ratio of the soft segment of fluoride exceed the critical value. Considering the above mentioned factors, the mechanical properties exhibit a tendency of increase at the beginning and then decrease with the increase of the ratio of soft segment containing fluorine in polyurethane.

\section{Water and oil repellency properties}

In the field of aviation, jet aircraft oil is a traditional fuel. Fluoropolymer often be used as a material for sealing aircraft fuel tanks. Therefore, it is necessary to use jet aircraft oil for the oil repellency test. Water resistance is also an important indicator of fluoropolymer. In order to test the water and oil repellency of polyurethane after introducing LFH, FPUs films were immersed into water and jet aircraft oil at $25^{\circ} \mathrm{C}$ for 22 days and $90^{\circ} \mathrm{C}$ for 48 hours, respectively. The weight change is showed in Table 3. After FPUs films being immersed into water, the weight change of fluorine-free FPU (FPU-1) was $2.50 \%$ at $25{ }^{\circ} \mathrm{C}$ for 22 days, whereas with the dosage of LFH increasing, the weight change of FPUs decreased gradually. When the dosage of LFH increased to $24 \mathrm{wt} \%$, the weight change of FPU-5 was only $1.79 \%$ at the same condition and $1.88 \%$ at $90{ }^{\circ} \mathrm{C}$ for $48 \mathrm{~h}$. At the same time, 
Table 3 Weight change of fluorinated polyurethane with different dosage of LFH in water and jet aircraft oil

\begin{tabular}{|c|c|c|c|c|c|}
\hline Dosage of LFH & 0 wt $\%$ & $6 \mathrm{wt} \%$ & $12 \mathrm{wt} \%$ & $18 \mathrm{wt} \%$ & $24 \mathrm{wt} \%$ \\
\hline Weight change/\% (water, $25^{\circ} \mathrm{C}, 22 \mathrm{~d}$ ) & 2.50 & 2.13 & 1.95 & 1.81 & 1.79 \\
\hline Weight change $/ \%$ (water, $90{ }^{\circ} \mathrm{C}, 48 \mathrm{~h}$ ) & 2.42 & 2.19 & 1.94 & 1.91 & 1.88 \\
\hline $\begin{array}{l}\text { Weight change } / \% \text { (jet aircraft oil, } 90^{\circ} \mathrm{C} \text {, } \\
48 \mathrm{~h} \text { ) }\end{array}$ & 1.69 & 1.51 & 1.40 & 1.32 & 1.02 \\
\hline
\end{tabular}
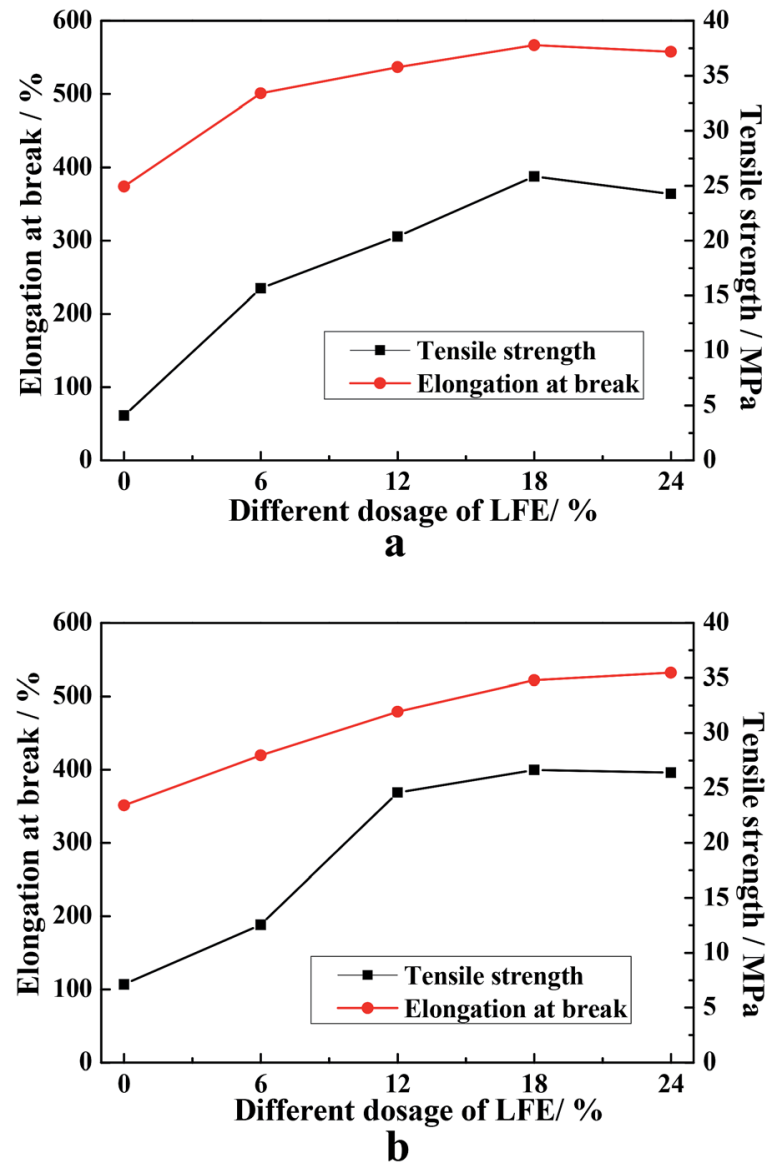

Fig. 7 Tensile strength and elongation at break curves of fluorinated polyurethane films with different dosage of LFH in water (a) and jet aircraft oil (b) $\left(90^{\circ} \mathrm{C}, 48 \mathrm{~h}\right)$.

when the media is jet aircraft oil, the weight change of fluorinefree FPU was $1.59 \%$ at $25{ }^{\circ} \mathrm{C}$ for 22 days and $1.69 \%$ at $90{ }^{\circ} \mathrm{C}$ for $48 \mathrm{~h}$. And with the dosage of LFH increasing, the weight change of FPUs decreased to $0.76 \%$ at $25{ }^{\circ} \mathrm{C}$ for $22 \mathrm{~d}$ and $1.02 \%$ at $90{ }^{\circ} \mathrm{C}$ for $48 \mathrm{~h}$. Obviously, the fluorine-containing soft segments could enhance the water and oil repellency of polyurethanes. Fluorine atoms have the characteristics of strong electronegativity, high $\mathrm{C}-\mathrm{F}$ bond energy $\left(540 \mathrm{~kJ} \mathrm{~mol}^{-1}\right)$, short atomic radius and protecting fluorine-carbon chain through shielding effect. According to the classic wetting theory, with the ratio of fluorinecontaining soft segment increasing, the surface energy of copolymer decreased, so the water and oil repellency of copolymer improved when the temperature below $100{ }^{\circ} \mathrm{C}$.
Fig. 7 showed the curve of tensile strength and elongation at break for samples after immerse into $90{ }^{\circ} \mathrm{C}$ water (a) and jet aircraft oil (b) for $48 \mathrm{~h}$. Compared with the black curve which stands for the mechanical parameters of FPUs at room temperature in Fig. 6, the two parameters in Fig. 7 all decreased, which may be caused by the hydrolysis and corrosive action of ester groups and carbamates after immerse into hot solvent for a long time. In addition, the added fluorine soft segment enhanced the strength of hydrogen bonds, and hydrophobic fluorine atoms prevented the water molecular contact with groups that easily hydrolyzable in polyurethane, further improving its hydrolysis resistance. Comparing the Fig. $7 a$ and $b$, it can be found that the tensile strengths of FPUs (FPU-3, FPU-4, FPU-5) immersed in jet aircraft oil at $90{ }^{\circ} \mathrm{C}$ for $48 \mathrm{~h}$ are higher than that of FPUs in water,
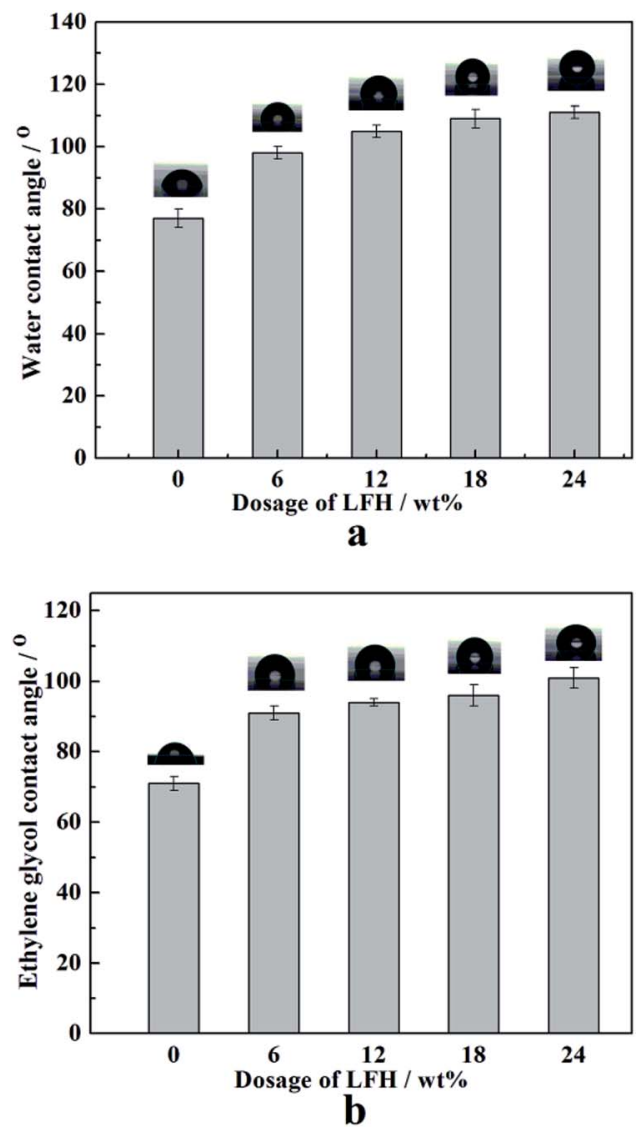

Fig. 8 Water (a) and ethylene glycol (b) CAs of the FPUs with different dosages of LFH. 
it demonstrates that the oil resistance of FPUs is stronger than the water resistance of FPUs due to the sensitive hydrolysis of FPUs.

\section{Surface properties}

Low surface energy and surface enrichment are two important characteristics of fluorinated polyurethane. Due to the migration of the fluorinated chain segments to the surface, the fluorine content in the surface of the material is enriched, so the fluorinated polyurethane has good hydrophobicity and lipophobicity. ${ }^{39}$ The static contact angle (CA) of FPU with different dosage of LFH were assessed by using the sessile drop method (Fig. 8). It can be found that the water CAs of the FPU films are $77^{\circ}, 98^{\circ}, 105^{\circ}, 109$ and $111^{\circ}$ respectively, and the ethylene glycol CAs of the FPU films are $71^{\circ}, 91^{\circ}, 94^{\circ}, 96^{\circ}$ and $101^{\circ}$ respectively. Obviously, as the dosage of LFH increase, both of the hydrophobicity and lipophobicity of FPU increase. What is more, with the increase of fluorine content, the surface energy of FPUs decreased rapidly. However, when the fluoride concentration reached a critical value, the change of membrane surface energy is very limited. This result demonstrates that only a small amount of fluorine-containing groups could highly change the surface properties of the polyurethane, which is very beneficial to reduce the cost of the product.

\section{Conclusion}

In this paper, a series of fluorinated polyurethanes (FPUs) containing two polyester polyols as soft segment were synthesized via a two-step method. The two polyester polyols were hydroxy-terminated liquid fluorine elastomer (LFH) and polytetrahydrofuran glycol (PTMG). Meanwhile, dibutyltin dilaurate (DBTEL) is used as the catalyst. FTIR and GPC results indicated that fluorinated groups have been introduced into the structure of copolymer, and all the monomers were copolymerized successfully. Water and ethylene glycol CAs showed that the surface properties change little when the dosage of LFH is higher than $6 \mathrm{wt} \%$. TGA, DMTA and conventional mechanic analysis showed that FPUs gained optimal thermal stability (thermal decomposition temperature of $304{ }^{\circ} \mathrm{C}$, char yield at $800{ }^{\circ} \mathrm{C}$ of $19 \%$ ) and mechanical property (tensile strength of 24.3 $\mathrm{MPa}$ ) when the dosage of $\mathrm{LFH}$ increases to a critical value (18 wt\%). Even after the cured films being immersed into hot water and oil, the FPUs also exhibit good mechanical property. This research could helps to achieve the balance between benefit and performance easily.

\section{Acknowledgements}

This work was financially supported by International Cooperative Project (Harbin Institute of Technology 2014DFR40370 and Wuxi HIT Limited Corporation \& Research Institute of New Materials BZ2015024).

\section{References}

1 C.-L. Wu, S.-H. Chiu, H.-T. Lee and M.-C. Suen, Polym. Adv. Technol., 2016, 27, 665-676.
2 T. Takakura, M. Kato and M. Yamabe, Macromol. Chem. Phys., 1990, 191(3), 625-632.

3 Z. Ge, X. Zhang, J. Dai, W. Li and Y. Luo, Eur. Polym. J., 2009, 45(2), 530-536.

4 E. Alyamac and M. D. Soucek, Prog. Org. Coat., 2011, 71, 213224.

5 J. Ge, Y. Si, F. Fu, J. Wang, J. Yang, L. Cui, B. Ding, J. Yu and G. Sun, $R S C$ Adv., 2013, 3, 2248-2255.

6 M. S. Shin, Y. H. Lee, M. M. Rahman and H. D. Kim, Polymer, 2013, 54, 4873-4882.

7 J. Li, X. Zhang, Z. Liu, W. Li and J. Dai, J. Fluorine Chem., 2015, 175, 12-17.

8 B. Ou, M. Chen, R. Huang and H. Zhou, RSC Adv., 2016, 6, 47138-47144.

9 J.-M. Park, Y.-H. Lee, H. Park and H.-D. Kim, J. Appl. Polym. Sci., 2014, 131, 40603.

10 Z. Wang, Z. Hou and Y. Wang, J. Appl. Polym. Sci., 2013, 127, 710-716.

11 H.-W. Engels, H.-G. Pirkl, R. Albers, R. W. Albach, J. Krause, A. Hoffmann, H. Casselmann and J. Dormish, Angew. Chem., Int. Ed., 2013, 52, 9422-9441.

12 Y. Wang and Y. Bai, RSC Adv., 2016, 6, 53730-53748.

13 A. Lovelace, British., 797795, 1958.

14 J. Hollander, F. Trischiler and R. Gosnell, J. Polym. Sci., 1967, 5, 2757.

15 T. Ho and K. Wynne, Macromolecules, 1992, 25, 3521.

16 C. Tonelli, G. Ajroldi, A. Turturro and A. Marigo, Polymer, 2001, 42, 5589.

17 C. Tonelli, G. Ajroldi, A. Turturro and A. Marigo, Polymer, 2001, 42, 9705.

18 C. Tonelli and G. Ajroldi, J. Appl. Polym. Sci., 2003, 87, 2279.

19 M. Bassi, C. Tonelli and A. Meo, Macromolecules, 2003, 36, 8015.

20 K. Chen and J. Kuo, Macromol. Chem. Phys., 2000, 202, 2676.

21 L. Wang, Eur. Polym. J., 2005, 40, 293.

22 L. Wang and Y. Wei, Colloids Surf., B, 2005, 402, 31.

23 H. Tan, X. Xie, J. Li, Y. Zhong and Q. Fu, Polymer, 2004, 45, 1495.

24 H. Tan, M. Guo, R. Du and X. Xie, Polymer, 2004, 45, 1647. 25 Y. Kim, J. Lee, Q. Ji and J. McGrath, Polymer, 2002, 43, 7161. 26 Y. Tang, J. Santerre, R. Labow and D. Taylor, J. Appl. Polym. Sci., 1996, 62, 1133.

27 H. Yeganeh and M. A. Shamekhi, Polymer, 2004, 45, 359-365. 28 P. I. Kordomenos, J. E. Kresta and K. C. Frisch, Macromolecules, 1987, 20, 2077-2083.

29 Y. Ma, Q.-Y. Tang, J. Zhu, L.-H. Wang and C. Yao, Chin. Chem. Lett., 2014, 25, 680-686.

30 A. Kausar, S. Zulfiqar and M. I. Sarwar, Polym. Degrad. Stab., 2013, 98, 368-376.

31 C.-e Yuan, M. Z. Rong and M. Q. Zhang, Polymer, 2014, 55, 1782-1791.

32 M. Xue, Y. Chen, Y. Si, Y. Li, H. Wan, J. Yu, G. Sun and B. Ding, RSC Adv., 2013, 3, 7562-7569.

33 L. Zhang, Y. Li, J. Yu and B. Ding, RSC Adv., 2015, 5, 7980779814.

34 J. Sheng, M. Zhang, W. Luo, J. Yu and B. Ding, RSC Adv., 2016, 6, 29629-29637. 
35 J. Ge, Y. Si, F. Fu, J. Wang, J. Yang, L. Cui, B. Ding, J. Yu and G. Sun, RSC Adv., 2013, 3, 2248-2255.

36 J. Li, Y. Lu, Y. Liu, Y. Li, W. You, C. Liu, L. Guo, X. Zhang and S. Qi, Polym.-Plast. Technol. Eng., 2014, 53, 46-53.

37 Z. Petrović, Z. Zavargo, J. Flyn and W. Macknight, J. Appl. Polym. Sci., 1994, 51, 1087-1095.

38 Y. Zhang, S. Shang, X. Zhang, D. Wang and D. Hourston, J. Appl. Polym. Sci., 1996, 59, 1167-1171.

39 E. Discekici, A. Anastasaki, R. Kaminker, J. Willenbacher, N. Truong, C. Fleischmann, B. Oschmann, D. Lunn, J. Alaniz, T. Davis, C. Bates and C. Hawker, J. Am. Chem. Soc., 2017, 139, 5939-5945.
40 L. Li, Y. Li, Y. Lan and J. Zhang, Chin. J. Magn. Reson., 2007, 24, 353-364.

41 C. Boyer, D. Valade, L. Sauguet, B. Ameduri and B. Boutevin, Macromolecules, 2005, 38, 10353-10362.

42 Y. Yuan, Chem. Propellants Polym. Mater., 2008, 6, 16-19. 43 ASTM Standard D4665-87, 1987.

44 T. Fischer and R. Krueger, Plaste Kautsch., 1988, 35, 342-348. 45 J. Xiong, F. Sun and H. Du, Chinese. J. Anal. Lab., 2007, 8, 7376.

46 H. Zhou, J. Tang, J. Zhang and W. Guo, Guangdong Chemistry, 2014, 21, 232-233. 